\title{
Resurgent nuclear threats
}

\author{
The world faces great risks from nuclear weapons that need to be urgently addressed by political leaders \\ and scientists worldwide. There is now a window of opportunity to do so.
}

f f any reminder was needed of today's nuclear threat, one need look no further than Pakistan, a country that possesses nuclear warheads, is riddled with Islamic extremism and stands on the brink of chaos. The world needs to ask itself the question posed in 2005 by Sam Nunn, former chairman of the Senate Armed Services Committee: on the day after a nuclear weapon goes off in one of our cities, what would we wish we had done to prevent it? That question challenges not only politicians but also those scientists who have the expertise and influence to help.

An analysis on page 114 explores the current status of the international framework to combat the new threats. It will be followed in weeks to come by articles that analyse aspects of the issue, and address what can be done.

Non-proliferation is a broad and complex issue, but the main imperatives for progress are all too starkly clear: no new nuclear weapons or weapons material; no new nuclear-weapons states; no role for nuclear weapons in foreign policy; and no 'loose nukes' - in other words, lock down and secure all existing weapons and stockpiles of weapons-grade material.

Political will is desperately needed, in particular for multilateral and international action. The 1992 US-Russian Cooperative Threat Reduction programme to secure and dismantle weapons and materials of mass destruction was a major step in the right direction, but its internationalization has so far extended to cleaning up a chemicalweapons dump in Albania. In 2004, the United Nations security council adopted a resolution requiring all states to implement national legislation making illegal all non-state activities to develop weapons of mass destruction. This April, states must report to the United Nations on their compliance, but it is expected that only a handful of countries have even begun to implement such legislation, not least because of a lack of hardware, expertise and surveillance.

\section{Manifesto for the future}

The cause of nuclear disarmament and non-proliferation was last year taken up by Nunn and three other prominent US statesmen: George Shultz and Henry Kissinger, former secretaries of state, and William Perry, a former secretary of defence. These unlikely political bedfellows, some of whom have previously been staunch advocates of nuclear might, have created a manifesto supporting the above four measures and more (see http://tinyurl.com/23o4ao). They want to take US and Russian missiles off alert, increase warhead cuts, quickly secure weapons material worldwide, ratify the Comprehensive Nuclear-Test-Ban Treaty, ban any further production of nuclearweapons material worldwide, stop rogue states acquiring military capacities under the guise of nuclear energy, and reinforce considerably the powers of the International Atomic Energy Agency.

All four statesmen are now convinced that, in the context of current threats, the nuclear arsenals of the five official nuclear-weapons states have become more of a liability than an asset. They embrace the position that those states must now, after a decade of fruitless vacillation, take the lead in substantially reducing their own nuclear postures and arsenals. This is not to appease aspiring nuclear powers such as Iran and North Korea, but is a considered strategy to win multilateral support for broader, tougher and faster measures on the major current threats of nuclear terrorism and nuclear proliferation.

The manifesto is both welcome and significant, not least because it represents an America that the world has not seen for too long, and one that could potentially transform international non-proliferation efforts. The proposals have had significant domestic influence, being cited regularly in the current
"The nuclear arsenals of the five official nuclear-weapons states have become more of a liability than an asset." US presidential campaign and broadly adopted as policy by all the leading Democratic candidates. But they have been largely unheard of outside the United States. One urgent need in support of the manifesto is to internationalize it.

\section{Vocal support}

Scientists have several critical roles to play. One is simply to be heard, both within government and the forums, but also more publicly, as independent voices - a role whose value was well demonstrated during the cold war between the United States and the Soviet Union. In contrast, for example, scientists and scientific organizations in southeast Asia and in India and Pakistan have not been prominent in issues of disarmament and non-proliferation. This, combined with the lack of non-governmental arms-control organizations in the region, has given the nuclear establishments in India and Pakistan a monopoly over expertise and advice, and inhibited open public debate.

Technological improvements are important too, in particular the enhancement of remote sensing to constantly monitor nuclear facilities. Technology could also help avoid political tensions by removing doubts one way or another about the motivations of a country's nuclear programme.

Scientists also need to work together internationally to develop new ideas. It is depressing that to find such collaboration in this context one has to look to Princeton University in New Jersey to find a programme bringing together Indian and Pakistani researchers to work on the nuclear threat. Here a handful are studying, for example, overly trigger-happy warning systems that could result in accidental firings within a three-minute decision window. They are also seeking to inform national policy-makers on the impact of a limited regional nuclear war, and to look at ways to limit a south Asian arms race.

With US elections this year, and negotiations getting under way for the 2010 review of the nuclear non-proliferation treaty, now is the time for scientists to make themselves heard. 